\title{
Oestrogen deficiency modulates particle-induced osteolysis
}

\author{
Christophe Nich ${ }^{1 *}$, Jean Langlois ${ }^{1}$, Arnaud Marchadier ${ }^{2,3}$, Catherine Vidal $^{3}$, Martine Cohen-Solal ${ }^{4}$, Hervé Petite ${ }^{1}$ and \\ Moussa Hamadouche
}

\begin{abstract}
Introduction: Postmenopausal osteoporosis may modulate bone response to wear debris. In this article, we evaluate the influence of oestrogen deficiency on experimental particle-induced osteolysis.

Methods: Polyethylene (PE) particles were implanted onto the calvaria of normal controls, sham-ovariectomized $(\mathrm{OVX})$, OVX mice and OVX mice supplemented with oestrogen (OVX+E). After 14 days, seven skulls per group were analyzed using a high-resolution micro-computed tomography (micro-CT) and histomorphometry, and for tartratespecific alkaline phosphatase. Five calvariae per group were cultured for the assay of IL-1 $\beta$, IL-6, TNF- $\alpha$ and receptor activator of the nuclear factor $\kappa B$ (RANKL) secretion using quantitative ELISA. Serum IL- 6 concentrations were obtained. The expression of RANKL and osteoprotegerin (OPG) mRNA were evaluated using real-time PCR.

Results: As assessed by $\mu \mathrm{CT}$ and by histomorphometry, PE particles induced extensive bone resorption and an intense inflammatory reaction in normal controls, sham-OVX and OVX+E mice, but not in the OVX mice group. In normal controls, sham-OVX and OVX+E mice, PE particles induced an increase in serum IL-6, in TNF- $\alpha$ and RANKL local concentrations, and resulted in a significant increase in RANKL/OPG messenger RNA (mRNA) ratio. Conversely, these parameters remained unchanged in OVX mice after PE implantation.

Conclusions: Oestrogen privation in the osteolysis murine model ultimately attenuated osteolytic response to PE particles, suggesting a protective effect. This paradoxical phenomenon was associated with a down-regulation of pro-resorptive cytokines. It is hypothesized that excessive inflammatory response was controlled, illustrated by the absence of increase of serum IL-6 in OVX mice after PE implantation.
\end{abstract}

\section{Introduction}

Aseptic loosening of total joint replacements develops as a consequence of periprosthetic osteolysis, caused by a macrophage-mediated inflammatory reaction $[1,2]$. Although it is well established that generation of polyethylene (PE) particles by the bearing couple is correlated with the risk for revision due to aseptic loosening [3], great variations in the degree of osteolysis are sometimes observed in clinical practice. This suggests that patient-related factors cause variability in the host response to PE particles. Authors have reported various factors, such as genetically determined obesity [4], and genetic background [5], as potential candidates involved in the modulation of host response to PE particles. In a

\footnotetext{
* Correspondence: chrnich@gmail.com

${ }^{1}$ Laboratoire de Bioingénierie et Biomécanique Ostéo-articulaires, Faculté de Médecine Paris 7-Denis Diderot, 10, avenue de Verdun, 75010 Paris, France Full list of author information is available at the end of the article
}

recent work, we evaluated the bone response to particulate debris in an ovariectomized mice model [6]. We hypothesized that high bone turnover driven by oestrogen deficiency following ovariectomy would result in accelerated bone loss in the area in contact with the PE particles. Paradoxically, particle-induced osteolysis was found significantly decreased in this model, indicating that ovariectomy could be protective against wear debris-induced osteolysis, possibly via sex steroid hormone deficiency. Particle-induced osteolysis has been shown to follow a biologic pathway, driven by cytokines such as interleukin (IL)-1 $\beta$, IL-6, and tumor necrosis factor (TNF) $-\alpha$. These mediators have been found in the soft tissue of joints with loosened prostheses [7] and appear to be released by human macrophage or macrophagelike cells in vitro [8]. There is evidence that the RANK (receptor activator of the nuclear factor $\kappa \mathrm{B}$ )/RANKL (RANK ligand) system acts downstream from IL-1, IL-6
C Biomed Central

(c) 2011 Nich et al.; licensee BioMed Central Ltd. This is an open access article distributed under the terms of the Creative Commons Attribution License (http://creativecommons.org/licenses/by/2.0), which permits unrestricted use, distribution, and reproduction in any medium, provided the original work is properly cited. 
and TNF- $\alpha$ and may be the ultimate effector mediating the effects of cytokines on the regulation of bone resorption [9]. Ovariectomy has been shown to decrease bone mass, stimulate bone remodeling, and increase IL6 levels in bone marrow [10,11], and to produce an osteoporotic bone phenotype, similar to postmenopausal osteoporosis. Interestingly, high levels of the three above-mentioned cytokins have been found in bone deprived of oestrogen [12].

Although the osteoprotective action of oestrogen is demonstrable in rodents, its implication in particleinduced osteolysis has never been shown. The purpose of the present study was to investigate the influence of oestrogen on the mechanism underlying particleinduced osteolysis in the murine calvaria model. Following our previous findings, we primarily hypothesized that oestrogen supplementation in ovariectomized mice would restore an extensive bone response to PE particles. In an attempt to shed light on possible underlying regulation, we secondly evaluated the local implication of the RANK/RANKL/OPG system and IL-1 $\beta$, IL-6, TNF- $\alpha$ cytokins.

\section{Materials and methods Particles}

Pure polyethylene particles (Ceridust VP 3620) were obtained from Clariant (Gersthofen, Germany). In our hands, the particle size was determined using scanning electron microscopy as previously detailed [6]. The mean particle size was $5.14 \mu \mathrm{m} \pm 3.05 \mu \mathrm{m}$ (median 4.39 $\mu \mathrm{m}$; range 0.52 to $15.5 \mu \mathrm{m}$ ). More than $55 \%$ of the particles were less than $5 \mu \mathrm{m}$ in size. All particles were washed in ethanol to remove endotoxins, and then dried in a dessicator [6]. This treatment resulted in negative testing for endotoxins using a quantitative Limulus Amebocyte Lysate (LAL) Assay (Charles River, Margate, UK) at a detection level of $<0.05 \mathrm{EU} / \mathrm{mL}$. Particles were stored at $4^{\circ} \mathrm{C}$ before implantation.

\section{Animal surgery and experimental protocol}

Eleven week-old C57BL/6J female mice $(n=96)$ were purchased from Janvier Laboratory (Le Genest-SaintIsle, France). All mice were handled in agreement with French and international guidelines for care and use of laboratory animals. The protocol was given ethical approval by the local Animal Care Committee. Fortyeight mice were subjected to bilateral ovariectomy (OVX group) via the dorsal approach under general anesthesia (isoflurane). Twenty-four mice were shamovariectomized (sham-OVX), that is, ovaries were exteriorized, but not removed. Twenty-four non-OVX mice constituted the normal control group. Animals were housed in quarantine under local vivarium conditions $\left(24^{\circ} \mathrm{C}\right.$ and $12 \mathrm{~h} / 12 \mathrm{~h}$ light/dark cycle) for one week.

Surgical implantation of PE particles has been previously described [4]. Briefly, mice were operated on under general anesthesia via inhaled isoflurane. All animals were 12 weeks old at surgery. A $0.5 \times 0.5 \mathrm{~cm}^{2}$ area of periostum was exposed by making a $10 \mathrm{~mm}$ midline sagittal incision over the calvaria. In PE-implanted groups, the particle powder $(20 \mu \mathrm{g})$ was distributed uniformly over the intact periosteum using a sterile sharp surgical spoon. Table 1 shows the treatment of the different experimental groups of mice. Postoperatively, 24 OVX animals, including 12 sham-implanted mice and 12 mice implanted with particles, were given subcutaneous oestrogen replacement therapy five days per week (15 $\mu \mathrm{g} 17$ beta-estradiol/kg body weight/day, Sigma Inc., St. Louis, MO, USA), and 24 OVX animals, including 12 sham-implanted mice and 12 mice implanted with particles, received subcutaneous vehicle only. Water and food were given ad libitum. Body weights were measured weekly, and the E injections were adjusted accordingly. Fourteen days postoperatively, the animals were sacrificed by an overdose of intraperitoneal sodium pentobarbital. The uteri were harvested and weighted to confirm oestrogen loss.

\section{Micro-computed tomography imaging and volumetric osteolysis analysis}

Seven calvariae per group were dissected after sacrifice. Specimens were freed of all soft tissues, and fixed in $4 \%$ neutralized paraformaldehyde. The skulls were analyzed with a high-resolution micro-computed tomograph (micro-CT) (Skyscan 1172; Skyscan, Aartselaar, Belgium) to perform qualitative and quantitative analyses of calvarial bone. Imaging analysis mainly focused on the osseous properties in the area of the skull sagittal suture. The radiographic projections $(n=210)$ were acquired at $80 \mathrm{kV}$ and $100 \mu \mathrm{A}$ with an exposure time

Table 1 Experimental mice groups

\begin{tabular}{|c|c|c|c|c|c|}
\hline & \multirow[t]{2}{*}{ Normal control group } & \multirow[t]{2}{*}{ Sham-OVX group } & \multicolumn{2}{|c|}{ OVX group } & \multirow[t]{2}{*}{ Total $(\mathrm{n})$} \\
\hline & & & OVX + Vehicle & $\mathrm{OVX}+\mathrm{E}$ & \\
\hline PE (-) & 12 & 12 & 12 & 12 & 48 \\
\hline$P E(+)$ & 12 & 12 & 12 & 12 & 48 \\
\hline Total (n) & 24 & 24 & 24 & 24 & 96 \\
\hline
\end{tabular}

$\mathrm{E}$, oestrogen; $\mathrm{PE}(-)$, sham-implanted; $\mathrm{PE}(+)$, $\mathrm{PE}$-implanted; OVX, ovariectomy. 
of $100 \mathrm{~ms}$. Eight frames were averaged for each rotation increment of $0.9^{\circ}$ to increase the signal to noise ratio. 3D images were reconstructed with a voxel average size of $10 \mu \mathrm{m}$, using the manufacturer reconstruction software (NRecon, Skyscan). Qualitative and quantitative data were analyzed with a global fixed threshold [13]. To minimize the bias from the 3D orientation of the calvaria, a spheric volume of interest (VOI of $2 \mathrm{~mm}$ diameter) with the midline suture of the skull in its center was defined, as previously described [6]. For quantitative analysis of PE particleinduced osteolysis, the resident software (CTAn, Skyscan) was used to obtain the following measurements within the VOI: bone volume $\left(\mathrm{BV}, \mathrm{mm}^{3}\right)$, and trabecular thickness (Tb.Th., mm). To address bone tissue mineralization following oestrogen depletion/substitution, a relative density measurement was computed. For this purpose, the mean value of grey-level intensity, reflecting the density of bone tissue, was obtained in entire calvariae.

\section{Histologic evaluation of osteolysis}

Calvariae were processed undecalcified after embedding in polymethyl-methacrylate according to a method previously described [6]. Sections $(10 \mu \mathrm{m})$ were obtained at the depth where the presence of particles was detected within the calvaria tissue. These sections were stained with Stevenel Blue and picrofuchsine and a serial section stained for tartrate-specific acid phosphatase-positive (TRAP) osteoclasts (Acid Phosphatase kit, SigmaAldrich, Steinheim, Germany). Using a magnification of $20 \times$, the histomorphometric analysis of each calvaria cap was performed on the most central section and on four adjacent sections. The region of interest was defined as previously recommended [4]. The sagittal suture area (SSA) was determined by tracing the area of soft tissue between the parietal bones. It included resorption pits on the superior surface of the calvaria visible in the same field as the midline suture. To determine bone thickness, sections were divided using a digital caliper in four $100 \mu \mathrm{m}$ steps to the left and right sides of the midline suture respectively. The measurements were expressed as a percentage of the mean ratio of bone thickness to the total tissue thickness (BT/TT) of the nine regional measurements in the five adjacent sections. To quantify bone loss, results were also expressed as a percentage of the mean difference of BT/TT $(\Delta$ $(\mathrm{BT} / \mathrm{TT}))$ between sham-operated and particleimplanted animals, in normal controls, sham-OVX, OVX, and OVX + E mice groups. Osteoclasts were identified as large multinucleated cells located on the bone perimeter within a resorption lacuna. Their localization was confirmed in a serial section stained for tartrate-specific acid phosphatase. The osteoclast number was measured in the region of interest of the five consecutive calvaria sections.

\section{Calvariae culture}

Calvariae were removed en bloc under sterile conditions from five animals per group randomly assigned for culture. Each calvaria was placed into one well of 12 wells/ plate and cultured with $1 \mathrm{ml}$ serum-and phenol-free Dulbecco's modified Eagle's medium (DMEM) with glutamine (Invitrogen, Paisley, UK), and $1 \%$ penicillin and streptomycin at $37^{\circ} \mathrm{C}$ and $5 \% \mathrm{CO} 2$ for $24 \mathrm{~h}$. Twenty four hours later, the culture medium was collected and stored at $-80^{\circ} \mathrm{C}$ for the assay of IL- $1 \beta$, IL-6, TNF- $\alpha$ and RANKL secretion. Then, calvariae were calcinated and ashes weighted to normalize the production of cytokines.

\section{ELISA for IL-1 $\beta$, IL- 6 , TNF- $\alpha$ and RANKL detection}

To measure IL- 6 concentration in serum, blood was obtained by cardiac puncture before death, and collected in heparinized tubes. Blood samples were then centrifuged at 3,000 $\times \mathrm{g}$ for 10 minutes, aliquoted and frozen at $-80^{\circ} \mathrm{C}$ until assayed. Serum measurements of IL-6 were performed using quantitative, noncompetitive, sandwich enzyme-linked immunosorbent assay kit for detecting mouse IL-6 (Quantikine, R\&D Systems Europe, Ltd, Abingdon, UK). Similarly, ELISA kits for detecting mouse IL- 6 , IL- $1 \beta$, TNF- $\alpha$ and RANKL (R\&D Systems) were employed to measure cytokines released into organ culture supernatant. The detection limits of the assay were $1.6 \mathrm{pg} / \mathrm{mL}$ for IL- $6,3 \mathrm{pg} / \mathrm{mL}$ for IL- $1 \beta$, $5.1 \mathrm{pg} / \mathrm{mL}$ for TNF- $\alpha$, and $5 \mathrm{pg} / \mathrm{mL}$ for RANKL. Cytokines levels lower than the detection limit were considered to be $0 \mathrm{pg} / \mathrm{ml}$. Absorbance was read in an ELISA reader (Micro-Quant, Bio-Tek Instruments, Colmar, France) at 490 and $540 \mathrm{~nm}$ as per manufacturer's instructions.

\section{Quantitative real-time polymerase chain reaction}

Calvariae were removed from culture medium, and immediately snap-frozen in liquid nitrogen, and pulverized to powder in a stainless steel mortar. RNA was extracted with $1 \mathrm{~mL}$ Trizol $^{\mathbb{B}}$ reagent (Invitrogen, Carlsbad, CA, USA), using the manufacturer's protocol. Quantity and purity of RNA was determined by absorbance on a NanoDrop ${ }^{\mathrm{TM}} 1000$ Spectrophotometer (Labtech France, Palaiseau, France) at 260 and $280 \mathrm{~nm}$. All samples had ratios $>1.7$ and were accepted for analysis.

Samples of total RNA were reverse-transcribed using the first-strand synthesis kit of SuperScript ${ }^{\mathrm{TM}}$ II Reverse Transcriptase (Invitrogen). Quantitative gene expression analyses were carried out using Real-time PCR by means of the TaqMan ${ }^{\mathrm{TM}}$ Gene Expression Assays Protocol (mouse RANK: Mm00437135_m1, mouse RANKL: 
Mm01313943_m1, mouse OPG: Mm01205928_m1, and human 18S rRNA: Hs99999901_s1; Applied Biosystems, Foster City, CA, USA) and the iCycler thermal cycler RT-PCR Detection System, coupled to MyiQ ${ }^{\mathrm{TM}}$ SingleColor software (Bio-Rad, Hercules, CA, USA). The absolute number of gene copies was normalized using $18 \mathrm{~s}$ rRNA and the relative quantification of the genes was calculated using the "comparative $C_{T}$ (threshold cycle) method" as per manufacturer's instructions (Applied Biosystems).

\section{Data analysis}

All values are presented as means \pm SEM. Quantitative parameters obtained from micro-CT (BV and Tb.Th) were analyzed by two-tailed Student's $t$-test within each group. Comparisons across unpaired groups were made according to the Mann-Whitney U test. Data concerning osteoclast number, sagittal suture area, and bone thickness were initially analyzed using a one-way analysis of variance (ANOVA). Post hoc comparison between groups used the Fisher's protected least significant difference. Two-way ANOVA was performed to determine whether there was a significant effect of either polyethylene particles or ovariectomy or oestrogen supplementation on osteoclast number, sagittal suture area and bone thickness. Cytokines concentrations and mRNAs expression were analyzed using one-way ANOVA followed by the Bonferroni/Dunnet's test. The level of statistical significance was set at $P<0.05$.

\section{Results}

\section{Changes after OVX}

All mice had increased body-weight by the end of the experiment. The final body-weight gain was $+18 \%$ in the OVX group as compared to $+6.8 \%(P<0.0001),+3.5 \%$ $(P<0.0001)$, and $+11 \%(P=0.0001)$ in normal controls, sham-OVX mice, and OVX $+\mathrm{E}$ mice, respectively.

At sacrifice, atrophy of uterine tissue was noted, indicating the effectiveness of oestrogen privation following ovariectomy. There was a significant difference in uterine weight in OVX mice group (mean, $24.5 \pm 3.6 \mathrm{mg}$ ), as compared to normal control animals (mean, $107.9 \pm$ $12 \mathrm{mg}, P<0.0001$ ), sham-OVX mice (mean, 86.4 \pm 17 mg, $P<0.0001$ ) and OVX + E mice (mean, $80.2 \pm 10.9$ mg, $P<0.0001)$. In contrast, uterine weight was notably less altered after oestrogen supplementation in OVX animals as compared to normal controls (80.2 \pm 10.9 mg versus $107.9 \pm 12 \mathrm{mg}, P=0.002$ ).

\section{Micro-CT evaluation of osteolysis}

Ovariectomy induced a consistent, although non-significant, decrease in mean grey-level intensity in calvariae without PE particles as compared to normal controls (Figure 1). Specifically, mean grey-level values were

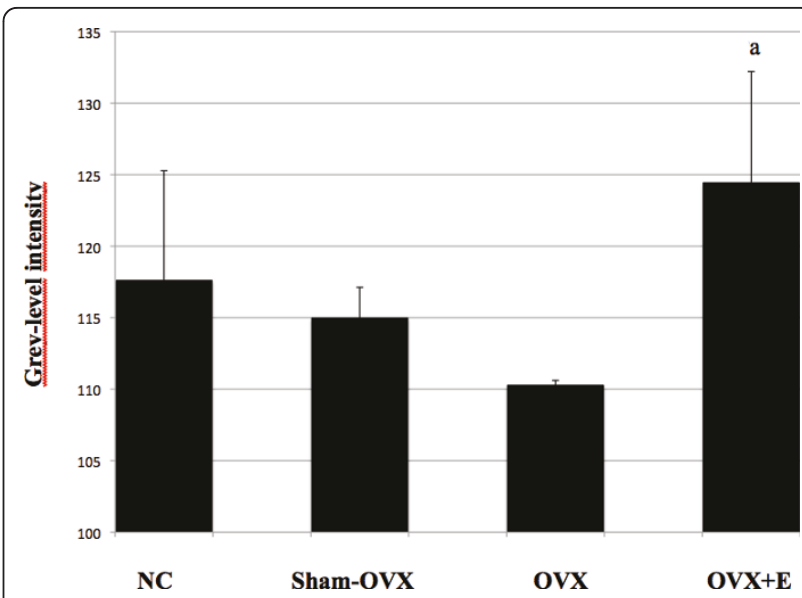

Figure 1 Grey-level intensity in entire calvariae, as assessed by 3D micro-CT. In the absence of PE particles, mean grey-level values decreased in ovariectomized (OVX) mice as compared to normal controls (NC) and Sham-OVX mice. Of note is the significant increase of grey-level intensity in calvarial bone tissue of OVX animals supplemented with oestrogen (E), as compared to OVX mice. Grey-level values were obtained using CTAn software. The data are presented as means \pm standard error of the mean (a indicates $P<0.05$, as compared to OVX mice, using the MannWhitney $U$ test).

$117.6 \pm 7.7$ (range, 107 to 48 ), $115 \pm 2$ (range, 107 to 120 ) and $110 \pm 0.3$ (range, 109 to 111 ), in normal controls, sham-OVX mice and OVX mice, respectively. In contrast, grey-level intensity significantly increased in OVX animals after oestrogen supplementation (124 \pm $7.8)$, as compared to OVX mice $(P=0.02)$, while it was similar to normal controls $(\{P=0.22)$ and sham-OVX mice $(P=0.07)$. The presence of PE particles induced profound changes in calvarial bone microarchitecture in all groups (Figure 2). In particle-implanted animals, BV significantly decreased within the VOI as compared to sham-implanted animals in normal control group $(P=$ $0.004)$, in sham-OVX group $(P=0.003)$, in OVX group $(P=0.04)$ and in OVX + E group $(P=0.001)$ (Figure 3$)$. However, decrease in BV following particle implantation was consistently less marked in the OVX group $(-7.8 \%$, as compared to $-21.2 \%$ in normal control group, $P=$ 0.04 , to $-19.9 \%$ in sham-OVX group, $P=0.003$, and to $-21.4 \%$ in OVX+E group, $P=0.005)$. Polyethylene particles did not produce any significant decrease in bone thickness (Tb.Th) in OVX mice $(+3.8 \%$ as compared to sham-implanted OVX mice, $P=0.08)$, in contrast with normal controls $(-13.6 \%$ as compared to shamimplanted normal controls, $P=0.01$ ), sham-OVX mice $(-11.1 \%$ as compared to sham-implanted sham-OVX mice, $P=0.008)$, and OVX $+\mathrm{E}$ group $(-11.6 \%$ as compared to sham-implanted OVX $+\mathrm{E}$ mice, $P=0.005)$ (Figure 4). 


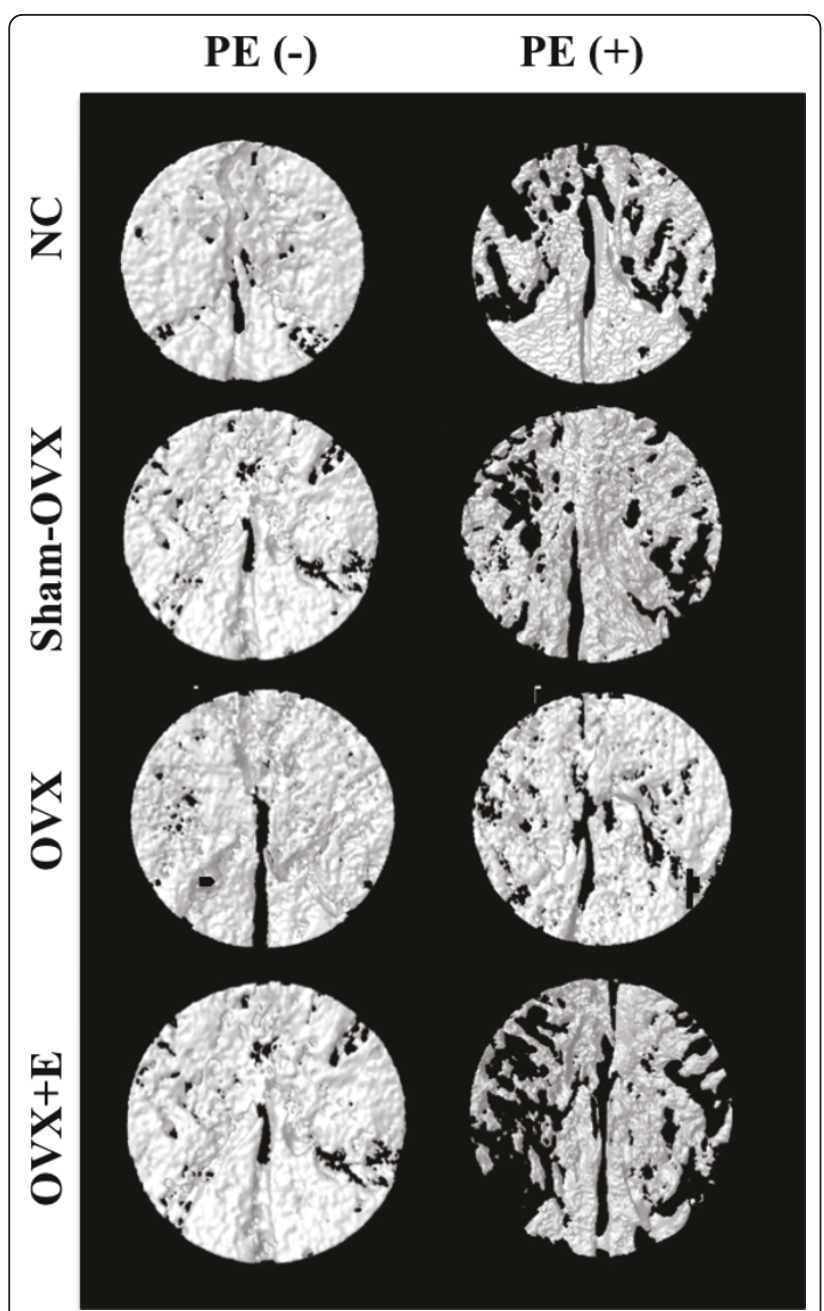

Figure 2 Effect of polyethylene particles on calvariae, as assessed by longitudinal 3D micro-CT. Representative

reconstructed images of the calvarial volume of interest (VOI), two weeks after sham-implantation (PE(-)) or PE particles implantation $(\mathrm{PE}(+))$ in different mice groups are shown ( $n=7$ per group). Of note is the consistent extent of bone resorption area following particles implantation in normal controls (NC), sham ovariectomized $(\mathrm{OVX})$ mice and $\mathrm{OVX}$ animals supplemented with oestrogen (E), while bone resorption area appears limited in OVX animals implanted with particles.

\section{Histology}

Histological sections showed a consistent erosion of the calvarial bone, associated to fibrous and granulomatous scar tissue layer on the periosteal side of the calvaria in particle-implanted mice, in all groups. The most dramatic lesions were observed when PE particles were implanted in the $\mathrm{OVX}+\mathrm{E}$ group (Figure 5). However, the tissue response to particles appeared limited in OVX animals without E supplementation. Using polarized light, many particles were found intracellularly within macrophages and foreign-body giant cells. TRAP

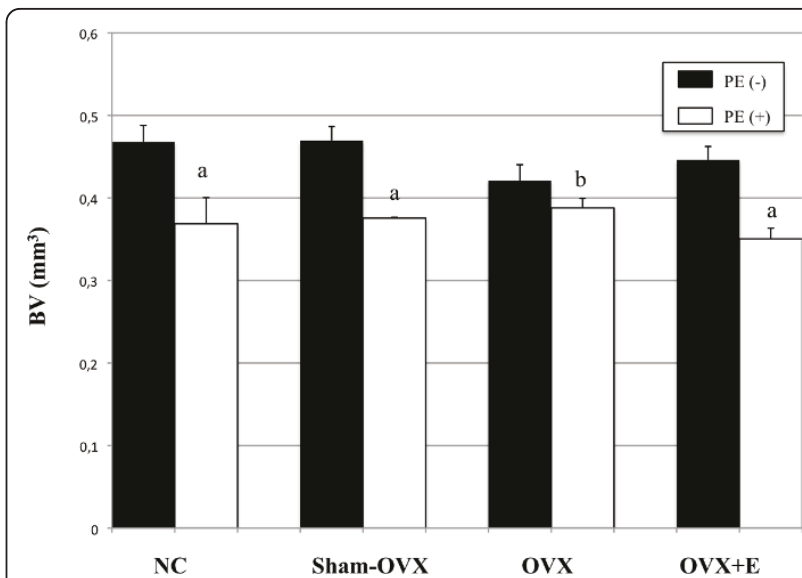

Figure 3 Effect of polyethylene particles on bone volume (BV), as assessed by longitudinal 3D micro-CT. Bone volume consistently decreased in all mice groups. However, bone loss was significantly lower in ovariectomized (OVX) mice as compared to normal controls (NC), sham-OVX mice and OVX animals supplemented with oestrogen (E). Bone volume was quantified using CTAn software. The data are presented as means \pm standard error of the mean (a indicates $P<0.005$; $\mathbf{b}$ indicates $P<0.05$, compared to internal control, using Student's t-test).

staining confirmed the presence of osteoclasts located in resorptive lacunae.

Histomorphometric data are shown in Table 2. Oneway ANOVA revealed a significant difference for the sagittal suture area $(P<0.0001)$. The presence of PE particles induced a significant increase in SSA in normal control group $(P<0.001)$, in sham-OVX group $(P<$ $0.001)$, in OVX group $(P<0.001)$, and in OVX+E group

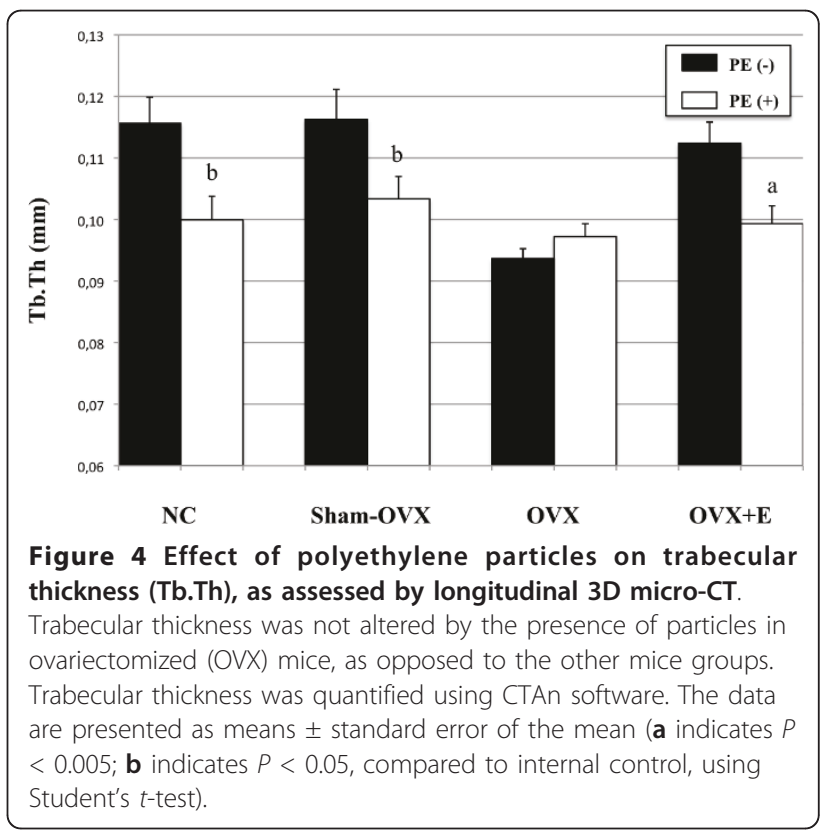




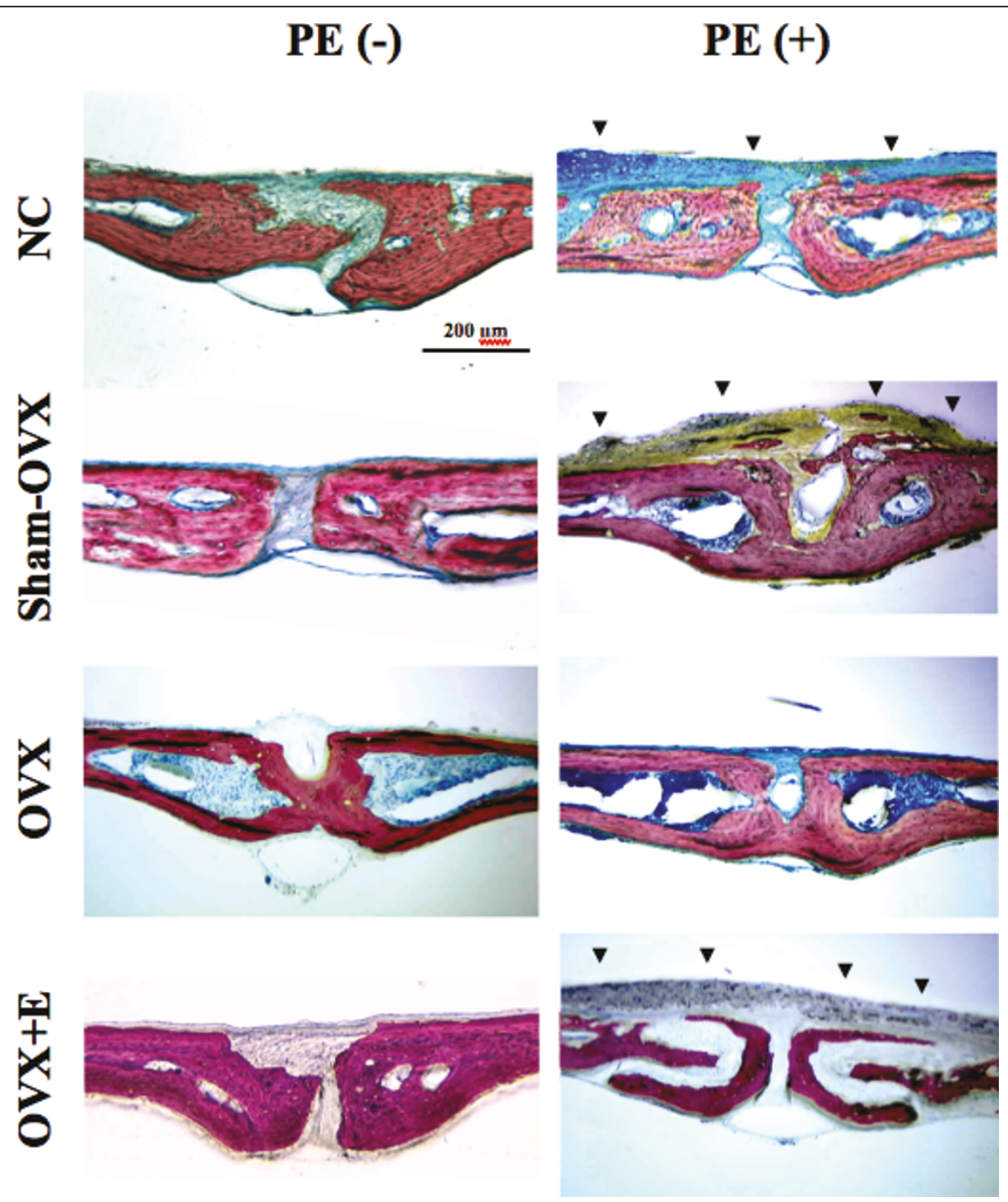

Figure 5 Effect of polyethylene particles on calvariae, as assessed by histology. Representative stained calvarial histology (Stevenel Blue, picrofuschine) is presented at $\times 20$ original magnification ( $n=7$ per group). Polyethylene particles induced osteolysis, characterized by a consistent decrease in calvarial bone thickness and an inflammatory response (arrowheads) in normal controls (NC), sham-ovariectomized (OVX) mice and OVX mice supplemented with oestrogen (E), while it was moderate in OVX mice. PE(-): sham-implanted; PE(+): PE-implanted.

Table 2 Histomorphometric results for each mice group

\begin{tabular}{|c|c|c|c|c|c|c|c|c|}
\hline & \multirow{2}{*}{\multicolumn{2}{|c|}{ Normal control group }} & \multirow{2}{*}{\multicolumn{2}{|c|}{ Sham-OVX group }} & \multicolumn{4}{|c|}{ OVX group } \\
\hline & & & & & \multicolumn{2}{|c|}{ OVX + Vehicle } & \multicolumn{2}{|c|}{$\mathrm{OVX}+\mathrm{E}$} \\
\hline & PE (-) & $\operatorname{PE}(+)$ & PE (-) & $\operatorname{PE}(+)$ & PE (-) & $P E(+)$ & PE (-) & $\operatorname{PE}(+)$ \\
\hline SSA $\left(\mathrm{mm}^{2}\right)$ & $\begin{array}{c}0.036 \pm 0.008 \\
(0.008 \text { to } .076)\end{array}$ & $\begin{array}{c}0.10 \pm 0.04 \\
(0.05 \text { to } 0.33)\end{array}$ & $\begin{array}{l}0.034 \pm 0.007 \\
(0.008 \text { to } 0.07)\end{array}$ & $\begin{array}{l}0.093 \pm 0.03 \\
(0.05 \text { to } 0.34)\end{array}$ & $\begin{array}{l}0.026 \pm 0.01 \\
(0.006 \text { to } 0.1)\end{array}$ & $\begin{array}{c}0.09 \pm 0.04 \\
(0.01 \text { to } 0.35)\end{array}$ & $\begin{array}{l}0.038 \pm 0.01 \\
(0.01 \text { to } 0.11)\end{array}$ & $\begin{array}{c}0.20 \pm 0.05 \\
(0.07 \text { to } 0.46)\end{array}$ \\
\hline $\mathrm{BT} / \mathrm{TT}$ & $\begin{array}{c}60 \pm 4.7 \% \\
(42 \% \text { to } 80 \%)\end{array}$ & $\begin{array}{c}48 \pm 5.3 \% \\
(23 \% \text { to } 73 \%)\end{array}$ & $\begin{array}{c}62 \pm 4.6 \% \\
(49 \% \text { to } 80 \%)\end{array}$ & $\begin{array}{c}45 \pm 4 \% \\
\text { (23\% to } 56 \%)\end{array}$ & $\begin{array}{c}55 \pm 5.2 \% \\
(35 \% \text { to } 73 \%)\end{array}$ & $\begin{array}{c}49 \pm 4.9 \% \\
\text { (26\% to } 65 \%)\end{array}$ & $\begin{array}{c}54 \pm 5.5 \% \\
\text { (31\% to } 73 \%)\end{array}$ & $\begin{array}{c}37 \pm 5.1 \% \\
(17 \% \text { to } 55 \%)\end{array}$ \\
\hline$\Delta(\mathrm{BT} / \mathrm{TT})$ & \multicolumn{2}{|c|}{$\begin{array}{c}-12 \pm 5.3 \% \\
(-37 \% \text { to } 12 \%)\end{array}$} & \multicolumn{2}{|c|}{$\begin{array}{l}-16 \pm 4.5 \% \\
(-39 \% \text { to } 5 \%)\end{array}$} & \multicolumn{2}{|c|}{$\begin{array}{c}-6.7 \pm 4.9 \% \\
(-30 \% \text { to } 9 \%)\end{array}$} & \multicolumn{2}{|c|}{$\begin{array}{c}-17 \pm 5 \% \\
(-37 \% \text { to } 1.2 \%)\end{array}$} \\
\hline $\mathrm{Oc} \mathrm{Nb}$ & $\begin{array}{l}0.31 \pm 0.3 \\
(0 \text { to } 2)\end{array}$ & $\begin{array}{l}2.2 \pm 0.7 \\
(0 \text { to } 5)\end{array}$ & $\begin{array}{l}0.42 \pm 0.3 \\
(0 \text { to } 2)\end{array}$ & $\begin{array}{l}2.5 \pm 0.7 \\
(0 \text { to } 5)\end{array}$ & $\begin{array}{c}0.65 \pm 0.4 \\
(0 \text { to } 3)\end{array}$ & $\begin{array}{l}0.7 \pm 0.5 \\
(0 \text { to } 4)\end{array}$ & $\begin{array}{l}0.27 \pm 0.2 \\
(0 \text { to } 1)\end{array}$ & $\begin{array}{l}2.1 \pm 0.8 \\
(0 \text { to } 6)\end{array}$ \\
\hline
\end{tabular}

Values are expressed as mean \pm standard error of the mean (extremes). BT, bone thickness; $\mathrm{E}$, oestrogen; Oc Nb, osteoclast number; OVX, ovariectomy; $\mathrm{PE}$, polyethylene; $\mathrm{PE}(-)$, sham-implanted; $\mathrm{PE}(+)$, $\mathrm{PE}$-implanted; SSA, sagittal suture area; $\Pi$, tissue thickness. 
$(P<0.0001)$. No significant difference was found in SSA between sham-implanted normal controls group and sham-implanted OVX group $(P=0.9)$, between PEimplanted normal control mice and PE-implanted OVX mice $(P=0.99)$, and between sham-implanted normal control mice and sham-implanted OVX + E mice $(P=1)$. Two-way ANOVA revealed a significant effect of PE particles on SSA $(P<0.0001)$. There was no independent effect of OVX on SSA $(P=1)$ in the absence of particles. One-way ANOVA revealed a significant difference for osteoclast number $(P<0.0001)$. The presence of PE particles induced a consistent increase in osteoclast number in normal control group $(P<0.0001)$, in sham-OVX group $(P<0.001)$, and in OVX + E group $(P$ $<0.0001)$, but not in OVX group $(P=0.99)$. There was also a significant effect of ovariectomy on osteoclast number $(P=0.047)$ in the absence of particles.

One-way ANOVA showed a significant difference for bone thickness $(P<0.0001)$. Implantation of PE particles resulted in a marked decrease in BT/TT in normal control group $(P=0.001)$, in sham-OVX group $(P<$ $0.001)$, and in OVX $+\mathrm{E}$ group $(P<0.0001)$. However, the presence of $\mathrm{PE}$ particles did not influence $\mathrm{BT} / \mathrm{TT}$ in OVX group $(P=0.088)$. Also, two-way ANOVA showed an independent effect of ovariectomy on BT/TT $(P<$ 0.001 ) in the absence of particles.

\section{Serum levels of IL-6}

Serum levels of IL-6 significantly increased after PE particles implantation in all mice groups, as compared with sham-implanted internal controls $(P=0.008$ in normal control group, $P=0.01$ in sham-OVX mice, and $P=$ 0.02 in OVX + E mice), except in OVX mice group $(P=$ 0.57 ) (Figure 6). Ovariectomy did not significantly increase serum IL- 6 concentrations in the absence of particle implantation (sham-implanted OVX group versus sham-implanted normal controls, $P=0.78$, and sham-implanted OVX $+E$ group versus sham-implanted normal control mice, $P=0.84$ ).

\section{Production of cytokines in organ culture}

The presence of PE particles induced a significant increase in IL-1 $\beta$ concentration in all mice groups (Figure 7). However, particles implantation did not significantly influence IL-6 media rates as compared to internal controls (Figure 7). In OVX mice without particles, the levels of TNF- $\alpha$ were significantly lower than in normal controls $(P=0.02)$. In addition, in this group, PE particles did not increase the rates of TNF- $\alpha(P=1)$, which remained considerably lower than in normal controls and in $\mathrm{OVX}+\mathrm{E}$ mice with $\mathrm{PE}$ particles $(P=0.002$ and $P=0.002$, respectively) (Figure 7 ). Significant differences in RANKL basal release (absence of particles implantation) were found between OVX mice and each

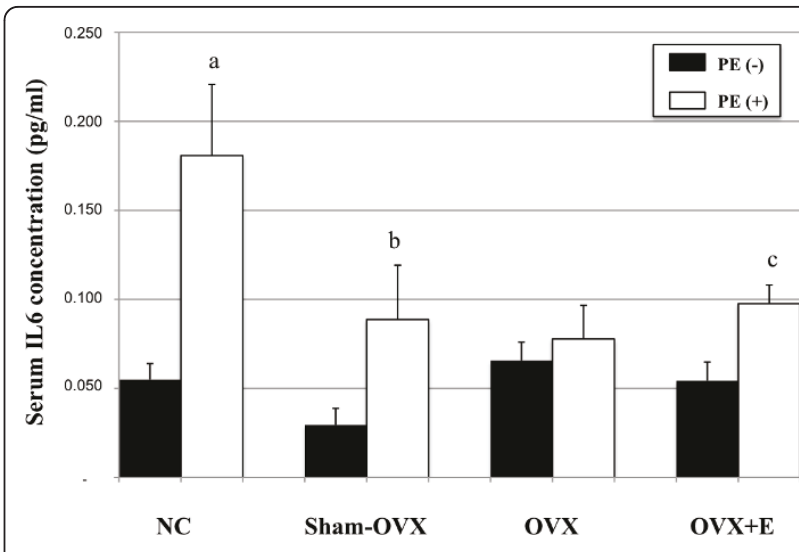

Figure 6 Effect of polyethylene particles on serum levels of IL6 in each mice group. Blood was obtained by cardiac puncture 14 days after surgery ( $n=5$ per group). Serum levels of IL-6 were determined by ELISA. Results are presented as mean \pm standard error of the mean (a indicates $P<0.01$; $\mathbf{b}$ indicates $P=0.01$; $\mathbf{c}$ indicates $P<0.005$, compared to internal control).

other mice groups (normal controls, $P=0.047$, shamOVX mice, $P=0.016$, OVX + E mice, $P=0.02)$. Noteworthy, RANKL local production appeared to be stimulated by $\mathrm{PE}$ particles in normal controls, in sham-OVX mice, and in OVX $+\mathrm{E}$ mice, while in OVX group, no significant modification in RANKL rates could be detected following particles implantation $(P=0.95)$ (Figure 7$)$.

\section{Quantitation of RANKL and OPG mRNA expressions in calvariae}

As shown in Figure 8, the combined effect of ovariectomy and PE particles implantation stimulated RANKL mRNA expression in calvariae, in all mice groups. However, PE-implanted calvariae in normal controls, shamOVX and OVX+E mice expressed RANKL mRNA at levels more than twice higher than OVX mice. OPG mRNA expression was not significantly different between groups (Figure 8). As a result, the RANKL/ OPG mRNA ratio significantly increased in all mice groups after PE implantation, but appeared consistently downregulated in OVX mice (Figure 8). The RANKL/ OPG mRNA ratio significantly differed between OVX mice and each other mice group in the absence of particles $(P=0.047$ as compared to normal controls, $P=$ 0.034 as compared to sham-OVX mice, and $P=0.049$ as compared to OVX+E mice). In addition, no significant difference could be observed in the basal RANKL/ OPG mRNA ratio between normal controls and OVX $+\mathrm{E}$ mice, indicating that $\mathrm{E}$ supplementation reestablished RANKL mRNA expression relative to OPG mRNA.

\section{Discussion}

In a recent work [6], we have shown that experimental stimulation of bone turnover by OVX resulted in a 

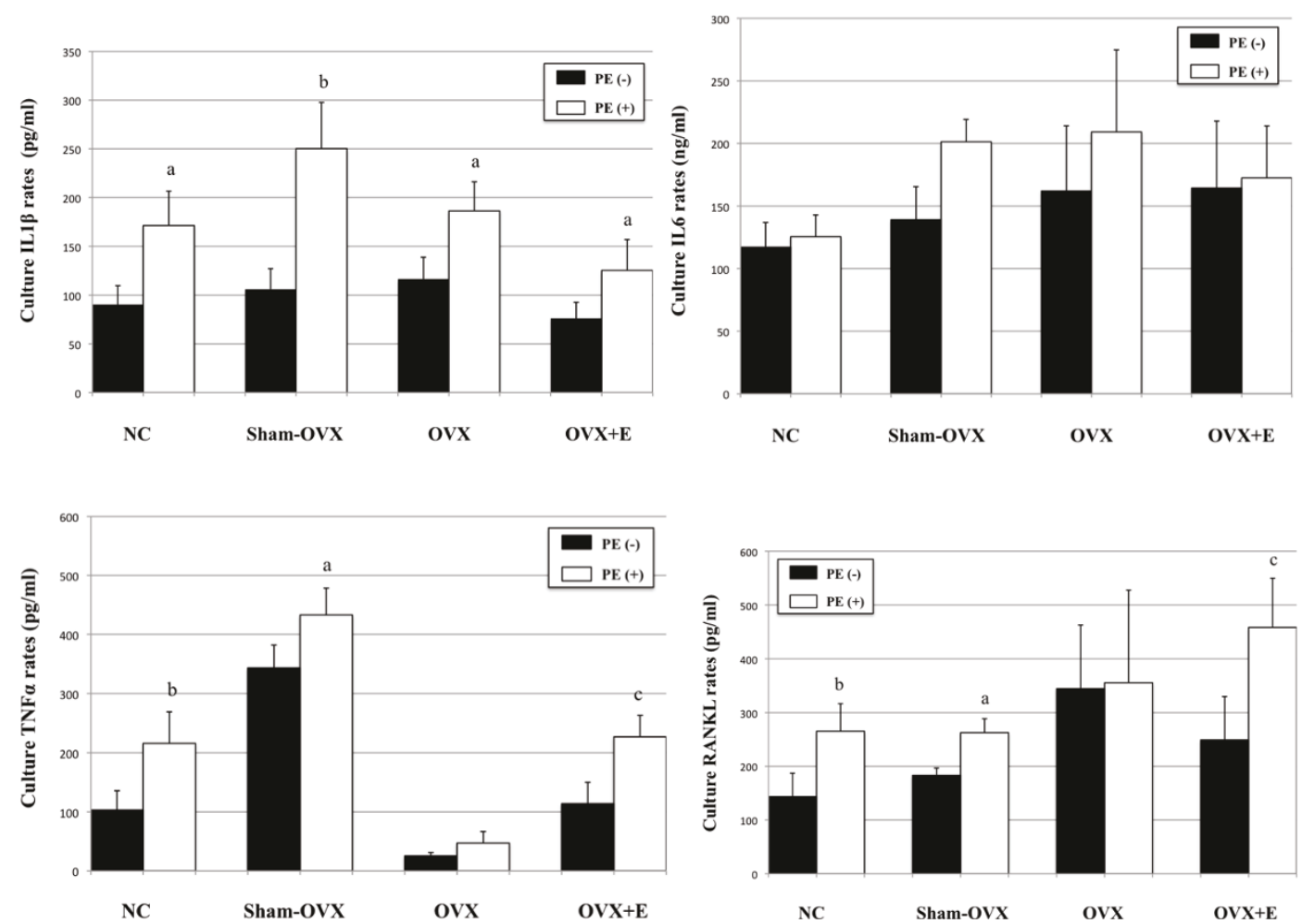

Figure 7 Effect of polyethylene particles on the local expression of IL-1 $\beta$, IL-6, TNF- $\alpha$ and RANKL (ELISA). Cytokines concentrations were determined after 24 hours in culture medium by ELISA ( $n=5$ per group). Results are presented as mean \pm standard error of the mean. $\mathbf{a}$ indicates $P<0.05$, $\mathbf{b}$ indicates $P<0.005$, $\mathbf{c}$ indicates $P=0.001$, compared to internal control. IL-1 $\beta$, interleukin $1 \beta$; IL-6, interleukin-6; TNF- $\alpha$, tumor necrosis factor- $\alpha$; RANKL, receptor activator of the nuclear factor $\kappa$ B ligand.

paradoxical decrease in particle-induced osteolysis in the murine calvaria model. To test the hypothesis that oestrogen-deficiency induced by OVX modulated the bone response to particulate debris, we supplemented PE particle-implanted OVX mice with $17 \beta$-estradiol. Then, we evaluated osteolysis and the involvement of the proinflammatory cytokines IL-6, IL- $1 \beta$, TNF- $\alpha$, and RANKL.

Our experiments show that the presence of PE particles induced an osteolytic reaction in bone calvaria in normal controls, in sham-OVX mice and in OVX $+\mathrm{E}$ mice, as illustrated by an extensive bone resorption and an intense inflammatory reaction involving both bone and periosteal tissue. In contrast, this process was considerably attenuated in OVX mice, with almost no modification in trabecular thickness, osteoclast number and periosteum thickness following PE implantation. In addition, Bone volume appeared consistently less altered following particles implantation, as compared to normal controls and OVX mice supplemented with oestrogen. Taken together, these data suggest that oestrogen deficiency influenced positively bone response to particulate debris. This finding appears paradoxical as clinical trials [14-16] and experimental studies $[17,18]$ have demonstrated the protective effects of oestrogen against inflammatory processes, such as rheumatoid arthritis (RA). However, the relationship between oestrogen and inflammation is controversial and might be related to a different response of bone and inflammation cells. Although it is admitted that oestrogen provides a protection against inflammation, it is also known that female patients are more prone to develop inflammatory diseases such as RA [19]. This point illustrates the dual action of oestrogen, both anti- and pro-inflammatory.

Numerous cellular and molecular mechanisms leading to bone resorption are common to osteolysis and oestrogen deficiency pathways. Cytokines such as IL-1, IL6, TNF- $\alpha$, and RANKL are up-regulated in both boneresorptive situations [20-24]. Differentiation of RANKLprimed osteoclasts precursors, activation of mature osteoclasts, and osteoclasts survival are enhanced by TNF- $\alpha$ [25]. Zhang et al. [26] showed that TNF- $\alpha$ and RANKL act synergistically on osteoclastogenesis in vitro. The role of TNF- $\alpha$ in OVX-induced bone loss is well documented $[20,27,28]$. Collectively, these studies suggest that up-regulation of TNF-producing cells in the bone marrow is a mechanism by which oestrogen deficiency induces bone loss. Indeed, functional blockade of 

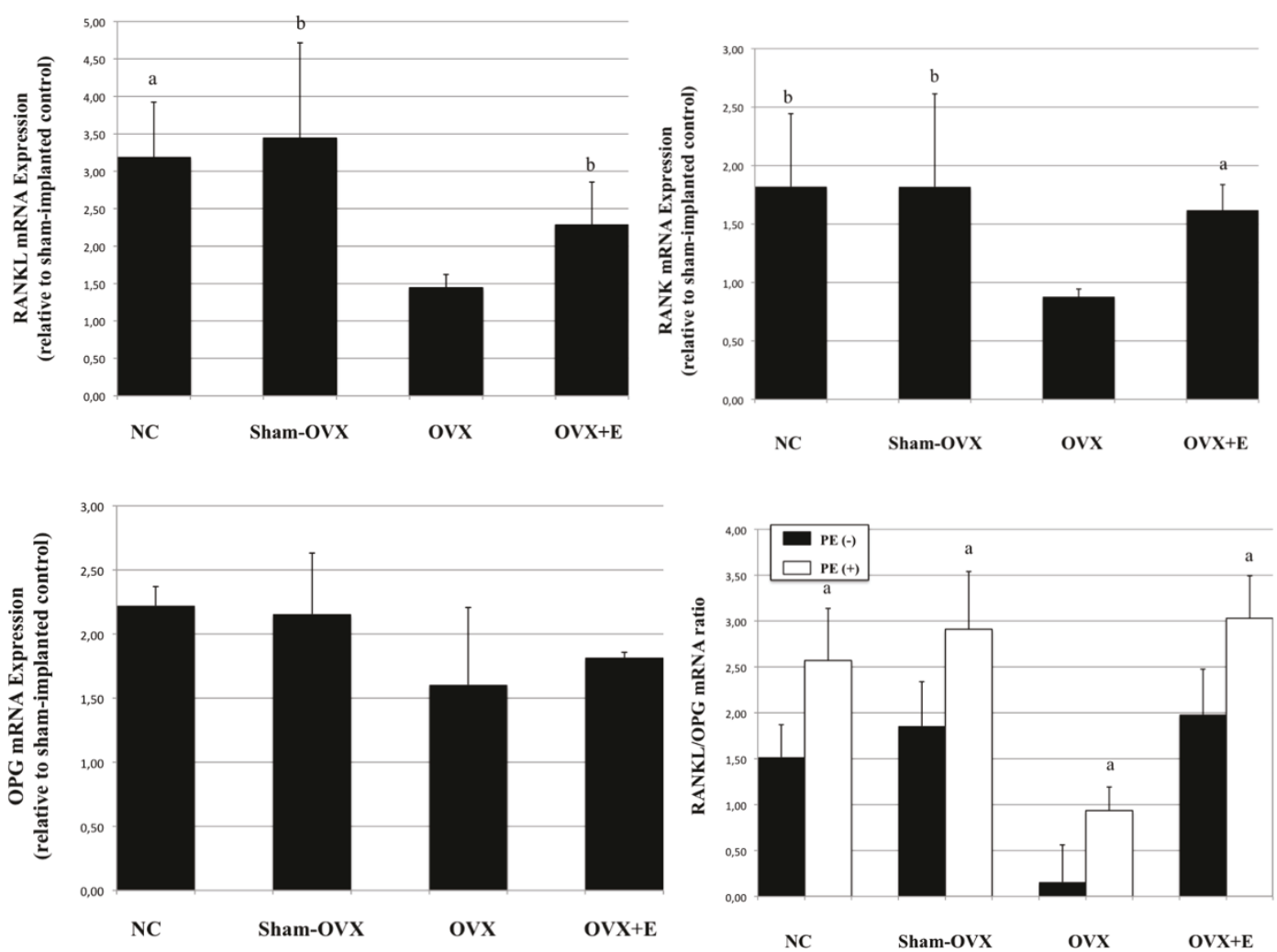

Figure 8 Effect of polyethylene particles on the expression of RANKL, RANK and OPG in bone calvariae. Quantitative real-time PCR analysis were performed 24 hours after calvariae culture ( $n=5$ per group). For every sample, experiments were carried out in triplicate and results are presented as mean \pm standard error of the mean. a indicates $P<0.05$, compared to sham-implanted internal controls. OPG, osteoprotegerin; RANK, receptor activator of the nuclear factor $\kappa B$; RANKL, RANK ligand.

TNF- $\alpha$ in mice leads to protection from OVX-induced bone loss [27]. Accordingly, we found that TNF- $\alpha$ local production was consistently altered in oestrogen deficient mice, suggesting its involvement in limited osteoclastogenesis in this group.

In our experiments, local release of pro-inflammatory cytokines IL1- $\beta$ and IL- 6 appeared heterogeneous. On one hand, we found that pro-inflammatory cytokine IL$1 \beta$ was stimulated by PE particles in all groups. On the other hand, IL-6 local rates were not increased in the presence of PE particles in any group. Indeed, it has been suggested that the involvement of pro cytokines in vivo may be difficult to demonstrate due to compensatory process [29], and to the delayed time course of release after particle implantation. Conversely, serum IL-6 was stimulated by PE implantation in normal controls, sham-OVX and E-supplemented OVX mice, whereas no significant change occurred in OVX mice. This point correlated well with the degree of osteolytic reaction combining bone resorption and periosteal inflammatory granuloma. The role of IL- 6 as a stimulator of bone resorption in post-menopausal osteoporosis is well-known [30]. IL-6 promotes bone resorption by affecting osteoclast differentiation and activity [31]. Our results are in line with clinical data showing that serum levels of IL-6 were consistently increased in patients with loosened hip prosthesis [32]. However, authors failed to correlate serum levels of IL- 6 and the volume of osteolysis [33]. These discrepancies suggest that serum cytokine levels may be influenced by various factors, such as cytokine release from other organs, and cytokine clearance rates from the joint. Taken together with our findings, we speculate that serum and local IL6 changes may be involved in the mechanism underlying the reduction of particle-induced osteolysis observed in OVX mice. Thus, the hormonal status appears as a key factor influencing serum IL-6 levels to be considered in further clinical studies.

We observed that the combination of two boneresorptive stimuli resulted in a down-regulation of local pro-resorptive cytokines TNF- $\alpha$ and RANKL, in parallel with a limitation of bone loss. The latter appeared as a consequence of decreased osteoclast activity and/or recruitment and/or accelerated apoptosis. We assume this process is regulated by the RANK/RANKL/OPG pathway, synergistically with TNF- $\alpha$ secretion, since 
RANKL is required for osteoclasts differentiation, survival and activity [21]. Pro-resorptive cytokine production could have been altered at the cellular level. Hence, particle-induced osteolysis and postmenopausal osteoporosis represent pro-inflammatory states with increased inflammatory cytokines and activated $\mathrm{T}$ cells [34]. Cytokines produced or regulated by $\mathrm{T}$ cells can enhance osteoclast formation by increasing the RANKL/OPG ratio [35]. Oestrogen deficiency also increases the RANKL/OPG ratio through increases in pro-inflammatory effectors, including IL- $1 \beta$, IL-6, IL-11, TNF- $\alpha$, MCSF and PGE [36]. RANKL expression was observed in osteoblasts/stromal cells and bone marrow in postmenopausal women. The molecular basis of the mechanism by which oestrogen deficiency induces accelerated osteoclastogenesis is not yet elucidated [37]. In mice, the selective ablation of oestrogen receptor in mature osteoclasts mimicked an osteoporotic bone phenotype [24], suggesting that oestrogen directly regulates the life span of differentiated osteoclasts, independently of an inflammatory pathway.

We hypothesize that the paradoxical decrease in bone response to PE particles in OVX mice could be driven by an innate protective mechanism that ultimately attenuated focal bone resorption. Hence, a tight control of innate immunity is essential because a disproportionate immune response may considerably compound morbidity. Recent studies suggested the involvement of $\mathrm{T}$ cells not only in pathogen clearance but also in regulating adaptative and innate immunity [38]. Recently, Guarda et al. [39] reported that excessive inflammation was suppressed by effector and memory $\mathrm{T}$ cells, via the blockade of mature IL-1 $\beta$ secretion, suggesting a possible mechanism for the control of excessive inflammatory responses.

We recognize limitations may have affected our findings. First, calvarial bone tissue considerably differs from long bone tissue with respect to cells, matrix composition and mineralization. Osteoclasts activity has been shown to be highly variable, depending on bone-site origin $[40,41]$. Specifically, it was reported that proteolytic enzymes used for bone matrix digestion [40,42], expression of TRAP enzyme, and size of osteoclasts originated from calvarial bone differed from those present in long bones [41,43]. Additionally, van den Bos et al. [44] reported that calvarial bone exhibited differences in matrix composition compared to long bone, including degree of mineralization, amounts of collagen, osteoglycin, and pigment epithelium derived factor. These data together indicate a putative difference in bone resorption characteristics in calvaria. Although the murine calvarial model has been extensively used to evaluate particle-induced osteolysis [4-6], the clinical relevance of our data should be considered with caution. Second, the osteolysis murine model does not fully reproduce the loading conditions of a prosthetic implant subjected to loosening. The consequences of OVX on mouse calvarial bone have been poorly studied. However, our observations revealed that basal calvarial bone thickness was significantly reduced in OVX mice, confirming previous findings $[10,45]$. This is consistent with bone resorption of the skull and subsequent parietal bone thinning observed in postmenopausal osteoporotic women [46]. Therefore, the current experimental protocol likely mimicked comparable cellular and biologic bone responses in OVX mice that occur in the early postmenopausal period. In the present work, we did not evaluate cytokines local rates in a time-dependant fashion after particles implantation. Hence, pro-inflammatory cytokines are known to be highly labile and, subsequently, their local and serum concentrations may vary with time. However, we limited our experiments to the time period preceding the onset of theoretical substantial bone repair. Therefore, it is likely that our cytokines and mRNA evaluations are compatible with bone cellular response tested in our model.

\section{Conclusions}

The present study analysed the consequences of oestrogen deprivation in a murine model of particle-induced osteolysis. We demonstrated that oestrogen deficiency significantly attenuated osteolytic response to PE particles. This phenomenon was associated with a down-regulation of pro-inflammatory and pro-resorptive cytokines TNF- $\alpha$ and RANKL, together with an absence of increase of serum IL-6. We favour the alternative that the combination of two bone-resorptive phenomenon altered cytokines production, possibly via the implication of the periosteum in this mice model.

\section{Abbreviations}

BT: bone thickness; BV: bone volume; CT: computed tomography; E:

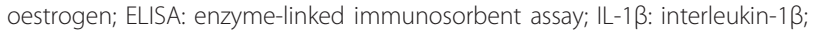
IL-6: interleukin-6; LAL: Limulus Amebocyte Lysate; OPG: osteoprotegerin; OVX: ovariectomy; PE: polyethylene; RANKL: RANK ligand; RANKL: receptor activator of the nuclear factor $\mathrm{KB}$; RT-PCR: real-time polymerase chain reaction; SSA: sagittal suture area; Tb.Th: trabecular thickness; TNF-a: tumor necrosis factor-a; TRAP: tartrate-specific acid phosphatase-positive; TT: tissue thickness; VOI: volume of interest.

\section{Acknowledgements}

The authors would like to thank Isabel Le Disquet, IFR de Biologie Intégrative, Service de Microscopie Electronique, Université Pierre et Marie Curie-Paris VI, for providing particles scanning electron microscopy analysis, and Laurent Havard, Service de Pharmacie, European Teaching Hospital, Paris, for providing particles decontamination and endotoxins tests.

\section{Author details}

Laboratoire de Bioingénierie et Biomécanique Ostéo-articulaires, Faculté de Médecine Paris 7-Denis Diderot, 10, avenue de Verdun, 75010 Paris, France. ${ }^{2}$ Useful Progress, 23, rue d'Anjou, 75008 Paris, France. ${ }^{3}$ Institut Pasteur and INSERM U747, Laboratory of Stem cells, Signaling and Prions, Université Paris 5-René Descartes, 45 Rue des Saints-Pères, 75270 Paris Cedex 06, France. 
${ }^{4}$ INSERM U606, Faculté de Médecine Paris 7-Denis Diderot, 10, avenue de Verdun, 75010 Paris, France.

\section{Authors' contributions}

$\mathrm{CN}$ carried out the histological experiments and analyses and drafted the manuscript. $J L$ carried out the cytokines measurements and RT-PCR. AM carried out micro-CT analyses. All other authors were involved in the design of the study, interpretation of the data and revision of the manuscript. All authors read and approved the final manuscript.

\section{Competing interests}

The authors declare that they have no competing interests.

Received: 4 January 2011 Revised: 17 May 2011

Accepted: 22 June 2011 Published: 22 June 2011

\section{References}

1. Willert HG, Bertram H, Buchhorn GH: Osteolysis in alloarthroplasty of the hip. The role of ultra-high molecular weight polyethylene wear particles. Clin Orthop Relat Res 1990, 258:95-107.

2. Schwarz EM, O'Keefe RJ, Looney RJ: Bone implant interface, osteolysis and potential therapies. J Musculoskelet Neuronal Interact 2004, 4:390-392.

3. Kobayashi S, Takaoka K, Saito N, Hisa K: Factors affecting aseptic failure of fixation after primary Charnley total hip arthroplasty. Multivariate survival analysis. J Bone Joint Surg Am 1997, 79:1618-1627.

4. von Knoch M, Jewison DE, Sibonga JD, Turner RT, Morrey BF, Loer F, Berry DJ, Scully SP: Decrease in particle-induced osteolysis in obese (ob/ ob) mice. Biomaterials 2004, 25:4675-4681.

5. Zhang C, Tang T, Ren W, Zhang X, Dai K: Influence of mouse genetic background on wear particle-induced in vivo inflammatory osteolysis. Inflamm Res 2008, 57:211-215.

6. Nich C, Marchadier A, Sedel L, Petite H, Vidal C, Hamadouche M: Decrease in particle-induced osteolysis in ovariectomized mice. J Orthop Res 2010, 28:178-183.

7. Ishiguro N, Kojima T, Ito T, Saga S, Anma H, Kurokouchi K, Iwahori Y, Iwase $\mathrm{T}$, Iwata $\mathrm{H}$ : Macrophage activation and migration in interface tissue around loosening total hip arthroplasty components. J Biomed Mater Res 1997, 35:399-406.

8. Green TR, Fisher J, Matthews JB, Stone MH, Ingham E: Effect of size and dose on bone resorption activity of macrophages by in vitro clinically relevant ultra high molecular weight polyethylene particles. J Biomed Mater Res 2000, 53:490-497.

9. Kwan Tat S, Padrines M, Theoleyre S, Heymann D, Fortun Y: IL-6, RANKL, TNFalpha/IL-1: interrelations in bone resorption pathophysiology. Cytokine Growth Factor Rev 2004, 15:49-60.

10. Wronski TJ, Dann LM, Scott KS, Cintrón M: Long-term effects of ovariectomy and aging on the rat skeleton. Calcif Tissue Int 1989, 45:360-366.

11. Passeri G, Girasole G, Jilka RL, Manolagas SC: Increased interleukin-6 production by murine bone marrow and bone cells after estrogen withdrawal. Endocrinology 1993, 133:822-828.

12. Spelsberg TC, Subramaniam M, Riggs BL, Khosla S: The actions and interactions of sex steroids and growth factors/cytokines on the skeleton. Mol Endocrinol 1999, 13:819-828.

13. Müller $R$, van Campenhout $H$, van Damme B, Van Der Perre G, Dequeker J, Hildebrand T, Rüegsegger P: Morphometric analysis of human bone biopsies: a quantitative structural comparison of histological sections and micro-computed tomography. Bone 1998, 23:59-66.

14. van den Brink HR, van Everdingen AA, van Wijk MJ, Jacobs JW, Bijlsma JW Adjuvant oestrogen therapy does not improve disease activity in postmenopausal patients with rheumatoid arthritis. Ann Rheum Dis 1993, 52:862-865.

15. Hall GM, Daniels M, Huskisson EC, Spector TD: A randomized controlled trial of the effect of hormone replacement therapy on disease activity in postmenopausal rheumatoid arthritis. Ann Rheum Dis 1994, 53:112-116.

16. D'Elia HF, Mattsson LA, Ohlsson C, Nordborg E, Carlsten H: Hormone replacement therapy in rheumatoid arthritis is associated with lower serum levels of soluble IL-6 receptor and higher insulin-like growth factor 1. Arthritis Res Ther 2003, 5:202-209.

17. Yoneda T, Ishimaru N, Arakaki R, Kobayashi M, Izawa T, Moriyama K, Hayashi Y: Estrogen deficiency accelerates murine autoimmune arthritis associated with receptor activator of nuclear factor-kappa B ligandmediated osteoclastogenesis. Endocrinology 2004, 145:2384-2391.

18. Subramanian S, Tovey M, Afentoulis M, Krogstad A, Vandenbark AA, Offner $\mathrm{H}$ : Ethinyl estradiol treats collagen-induced arthritis in DBA/1LacJ mice by inhibiting the production of TNF-alpha and IL-1beta. Clin Immunol 2005, 115:162-172.

19. da Silva JA, Willoughby DA: The influence of sex in arthritis: is cartilage an overlooked factor? J Rheumatol 1994, 21:791-796.

20. Kimble RB, Srivastava S, Ross FP, Matayoshi A, Pacifici R: Estrogen deficiency increases the ability of stromal cells to support murine osteoclastogenesis via an interleukin-1 and tumor necrosis factormediated stimulation of macrophage colony-stimulating factor production. J Biol Chem 1996, 271:28890-28897.

21. Kong YY, Feige U, Sarosi I, Bolon B, Tafuri A, Morony S, Capparelli C, Li J, Elliott R, Mc Cabe S, Wong T, Campagnuolo G, Moran E, Bogoch ER, Van G, Nguyen LT, Ohashi PS, Lacey DL, Fish E, Boyle WJ, Penninger JM: Activated $T$ cells regulate bone loss and joint destruction in adjuvant arthritis through osteoprotegerin ligand. Nature 1999, 402:304-309.

22. Li J, Sarosi I, Yan XQ, Morony S, Capparelli C, Tan HL, McCabe S, Elliott R, Scully S, Van G, Kaufman S, Juan SC, Sun Y, Tarpley J, Martin L, Christensen K, Mc Cabe J, Kostenuik P, Hsu H, Fletcher F, Dunstan CR, Lacey DL, Boyle WJ: RANK is the intrinsic hematopoietic cell surface receptor that controls osteoclastogenesis and regulation of bone mass and calcium metabolism. Proc Natl Acad Sci USA 2000, 97:1566-1571.

23. Teitelbaum SL: Osteoclasts, integrins, and osteoporosis. J Bone Miner Metab 2000, 18:344-349.

24. Nakamura T, Imai $Y$, Matsumoto $T$, Sato $S$, Takeuchi $K$, Igarashi $K$, Harada $Y$, Azuma Y, Krust A, Yamamoto Y, Nishina H, Takeda S, Takayanagi H, Metzger D, Kanno J, Takaoka K, Martin TJ, Chambon P, Kato S: Estrogen prevents bone loss via oestrogen receptor alpha and induction of Fas ligand in osteoclasts. Cell 2007, 130:811-823.

25. Childs LM, Goater JJ, O'Keefe RJ, Schwarz EM: Efficacy of etanercept for wear debris-induced osteolysis. J Bone Miner Res 2001, 16:338-347.

26. Zhang YH, Heulsmann A, Tondravi MM, Mukherjee A, Abu-Amer Y: Tumor necrosis factor-alpha (TNF) stimulates RANKL-induced osteoclastogenesis via coupling of TNF type 1 receptor and RANK signaling pathways. J Biol Chem 2001, 276:563-568.

27. Kimble RB, Matayoshi AB, Vannice JL, Kung VT, Williams C, Pacifici R: Simultaneous block of interleukin-1 and tumor necrosis factor is required to completely prevent bone loss in the early postovariectomy period. Endocrinology 1995, 136:3054-3061.

28. Roggia C, Gao Y, Cenci S, Weitzmann MN, Toraldo G, Isaia G, Pacifici R: Upregulation of TNF-producing $T$ cells in the bone marrow: a key mechanism by which oestrogen deficiency induces bone loss in vivo. Proc Natl Acad Sci USA 2001, 98:13960-13965.

29. Taki N, Tatro JM, Lowe R, Goldberg VM, Greenfield EM: Comparison of the roles of IL-1, IL-6, and TNFalpha in cell culture and murine models of aseptic loosening. Bone 2007, 40:1276-1283.

30. Lerner UH: Inflammation-induced bone remodeling in periodontal disease and the influence of post-menopausal osteoporosis. J Dent Res 2006, 85:596-607.

31. Lorenzo J: Interactions between immune and bone cells: new insights with many remaining questions. J Clin Invest 2000, 106:749-752.

32. Hernigou P, Intrator L, Bahrami T, Bensussan A, Farcet JP: Interleukin-6 in the blood of patients with total hip arthroplasty without loosening. Clin Orthop Relat Res 1999, 366:147-154.

33. Tanaka R, Yasunaga Y, Hisatome T, Yamasaki T, Iwamori H, Ochi M: Serum interleukin 8 levels correlate with synovial fluid levels in patients with aseptic loosening of hip prosthesis. J Arthroplasty 2005, 20:1049-1054.

34. Cenci S, Weitzmann MN, Roggia C, Namba N, Novack D, Woodring J, Pacifici R: Estrogen deficiency induces bone loss by enhancing T-cell production of TNF-alpha. J Clin Invest 2000, 106:1229-1237.

35. Weitzmann MN, Pacifici R: The role of T lymphocytes in bone metabolism. Immunol Rev 2005, 208:154-168.

36. Pacifici R: Estrogen, cytokines, and pathogenesis of postmenopausal osteoporosis. J Bone Miner Res 1996, 11:1043-1051.

37. Sato T, Watanabe K, Masuhara M, Hada N, Hakeda Y: Production of IL-7 is increased in ovariectomized mice, but not RANKL mRNA expression by osteoblasts/stromal cells in bone, and IL-7 enhances generation of osteoclast precursors in vitro. J Bone Miner Metab 2007, 25:19-27. 
38. Kim KD, Zhao J, Auh S, Yang X, Du P, Tang H, Fu YX: Adaptive immune cells temper initial innate responses. Nat Med 2007, 13:1248-1252.

39. Guarda G, Dostert C, Staehli F, Cabalzar K, Castillo R, Tardivel A, Schneider P, Tschopp J: T cells dampen innate immune responses through inhibition of NLRP1 and NLRP3 inflammasomes. Nature 2009, 460:269-273.

40. Everts V, de Vries TJ, Helfrich MH: Osteoclast heterogeneity: lessons from osteopetrosis and inflammatory conditions. Biochim Biophys Acta 2009, 1792:757-765.

41. de Souza Faloni AP, Schoenmaker T, Azari A, Katchburian E, Cerri PS, de Vries TJ, Everts V: Jaw and long bone marrows have a different osteoclastogenic potential. Calcif Tissue Int 2011, 88:63-74.

42. Everts V, Korper W, Hoeben KA, Jansen ID, Bromme D, Cleutjens KB, Heeneman S, Peters C, Reinheckel T, Saftig P, Beertsen W: Osteoclastic bone degradation and the role of different cysteine proteinases and matrix metalloproteinases: differences between calvaria and long bone. J Bone Miner Res 2006, 21:1399-1408.

43. Perez-Amodio S, Jansen DC, Schoenmaker T, Vogels IM, Reinheckel T, Hayman AR, Cox TM, Saftig P, Beertsen W, Everts V: Calvarial osteoclasts express a higher level of tartrate-resistant acid phosphatase than long bone osteoclasts and activation does not depend on cathepsin $\mathrm{K}$ or $\mathrm{L}$ activity. Calcif Tissue Int 2006, 79:245-254.

44. van de Bos T, Speijer D, Bank RA, Bromme D, Everts V: Differences in matrix composition between calvaria and long bone in mice suggest differences in biomechanical properties and resorption: Special emphasis on collagen. Bone 2008, 43:459-468.

45. Libouban H, Moreau MF, Baslé MF, Bataille R, Chappard D: Increased bone remodeling due to ovariectomy dramatically increases tumoral growth in the 5T2 multiple myeloma mouse model. Bone 2003, 33:283-292.

46. Takata S, Takao S, Yoshida S, Hayashi F, Yasui N: Therapeutic effects of one-year alendronate treatment in three cases of osteoporosis with pariétal thinning of skull. J Med Invest 2008, 55:297-302.

doi:10.1186/ar3381

Cite this article as: Nich et al:: Oestrogen deficiency modulates particleinduced osteolysis. Arthritis Research \& Therapy 2011 13:R100.

\section{Submit your next manuscript to BioMed Central and take full advantage of:}

- Convenient online submission

- Thorough peer review

- No space constraints or color figure charges

- Immediate publication on acceptance

- Inclusion in PubMed, CAS, Scopus and Google Scholar

- Research which is freely available for redistribution

Submit your manuscript at www.biomedcentral.com/submit
Biomed Central 